\title{
Os Excessos de Elena: O Ensaio e o Devir Mulher na Obra de Petra Costa
}

\author{
Juliana Gusman \\ Doutoranda em Meios e Processos \\ Audiovisuais pela Universidade de \\ São Paulo. Mestre em Comunicação \\ Social pela Pontifícia Universidade \\ Católica de Minas Gerais. Bacharel em \\ Comunicação Social, com habilitação \\ em Jornalismo, pela mesma instituição. \\ É membro do grupo de pesquisa Mídia e \\ Narrativa e da Rede Metacrítica. \\ E-mail: jugusman@terra.com.br.
}

Resumo: Este artigo pretende problematizar como o devir feminino é trabalhado no documentário Elena (2012), de Petra Costa. O filme, de corte ensaístico e (auto)biográfico, almeja reflexionar sobre as agruras do processo de "vir a ser mulher", lançando mão de diferentes matérias de expressão articuladas criticamente para tensionar padrões culturais de gênero violentos. Isso posto, objetiva-se analisar não apenas a obra em si, mas também discursos que a tangenciam. Investigarei como outras narrativas audiovisuais especificamente um conjunto de treze vídeos divulgados nas redes oficiais do filme extrapolam e excedem os conteúdos do documentário, exercendo uma função paratextual. Supõe-se que Elena, além de propor questões centrais à emancipação feminina, consegue potencializar, por meio dos seus "excessos", sua própria circulação e mediação social.

Palavras-chave: Elena, documentário de mulheres, ensaio audiovisual, autobiografia, feminismo.

\section{Los Excesos de Elena: El Ensayo y el Devenir Mujer en la Obra de Petra Costa}

Resumen: Este artículo pretende problematizar cómo se trabaja el devenir femenino en el documental Elena (2012), de Petra Costa. La película, ensayista y autobiográfica, tiene como objetivo reflexionar sobre las dificultades del proceso de "volverse mujer", utilizando diferentes materiales de expresión articulados críticamente para tensar patrones culturales violentos de género. Dicho esto, el objetivo no es analizar solo la obra en sí, sino también los discursos. Se aborda cómo otras narrativas audiovisuales un conjunto de trece vídeos publicados en las redes oficiales de la película- superan los contenidos del documental, ejerciendo una función paratextual. Se supone que Elena, además de proponer temas centrales para la emancipación femenina, logra potenciar en sus "excesos" su propria circulación y mediación social.

Palabras-clave: Elena, documental de mujeres, ensayo audiovisual, autobiografía, feminismo.

\section{The excesses of Elena: Essay and womanhood in the work of Petra Costa}

Abstract: This article aims to problematize how the process of becoming a woman is approached in Elena (2012), a documentary by Brazilian filmmaker Petra Costa. Using different filmic materials critically articulated to tension violent gender norms, the movie, essayistic and autobiographical, intends to reflect upon the hardships of that process. In this sense, this paper aims to analyze the movie itself and a set of thirteen complementary audiovisual narratives released on the Internet that exceed the contents of the documentary, exercising a paratextual function. Besides highlighting important aspects of female emancipation, Elena manages do enhance, through its "excesses", its own circulation and social mediation.

Keywords: Elena, women's documentary, film essay, autobiography, feminism. 
Todo ser humano do sexo feminino não é, portanto, necessariamente mulher; cumpre-lhe participar dessa realidade misteriosa e ameaçada que é a feminilidade. Será esta secretada pelos ovários? Ou estará congelada no fundo de um céu platônico? E bastará uma saia de fru-fru para fazê-la descer à Terra? (Beauvoir, 2016, p. 10)

Em determinado momento de Elena (2012), Petra Costa, em sua narração-carta à irmã morta que nomeia a obra, se pergunta: "qual o meu papel nesse filme?". Se a resposta não é simples, ou sequer solucionável, a pergunta reticente é, também, mais abstrusa do que se pode aferir. Será que Petra se refere ao seu papel como uma diretora em busca da reconstituição de Elena - que se suicidou nos anos 1990, em Nova York, aos 20 anos -, no emaranhamento não apenas dos fios elétricos do seu sonho com a irmã, mas de uma complexa arqueologia dos rastros e registros da jovem aspirante a atriz de Hollywood? Seria essa uma indagação sobre o objetivo último do documentário, de corporificar a memória e o trauma que a infância de Petra, que tinha apenas sete anos quando Elena morreu, não conseguiu preservar? Ou seria sobre qual papel performa Petra, que reencena e reencarna a irmã, cujo destino sempre assombrou e se confundiu com o da diretora? Quem é Petra? Quem é Elena?

Antes de ser um filme sobre suicídio, Elena talvez seja, como definiu Eliane Brum (2014), um filme sobre a procura - e a perda - do próprio corpo, sobre "a trajetória de uma mulher em busca de ser não mais duas, mas uma." (Brum, 2014, p. 18). O documentário, de corte ensaístico e (auto)biográfico, busca refletir sobre um devir feminino, ou devir mulher, que parece se sobressair como questão medular nesta produção cinematográfica, ponto que pretendo, neste artigo, problematizar. Não obstante, tomarei como referência não apenas a obra em si, mas também alguns discursos que a tangenciam. Na ocasião do lançamento, Petra Costa divulgou, tanto no canal do YouTube, quanto no site oficial do filme, uma série de treze vídeos, ordenados tematicamente, com trechos que foram cortados de Elena. Trata-se de entrevistas, registros de performances, materiais de arquivo na íntegra e depoimentos sobre a feitura do documentário. Tomando emprestado um conceito da literatura, podemos dizer que essas pílulas audiovisuais operam como paratextos (Genette, 2018), como uma espécie de "franja" da narrativa principal, que interferem na sua acolhida e propõem novas reflexões sobre ela.

Meu objetivo é problematizar como esses vídeos - estes excessos de Elena podem orientar leituras e espectatorialidades do documentário, interferindo em seu caráter ensaístico e, consequentemente, no tratamento dos dilemas que atravessam o processo inexorável do "vir a ser mulher". Tenciono analisar como materiais audiovisuais que extrapolam a obra podem potencializar tanto o argumento fulcral de Elena, como a leitura que podemos efetuar a partir de sua fruição.

\section{As mulheres e o documentário}

O filme de Petra Costa, em verdade, ressoa experiências similares no campo do documentário brasileiro contemporâneo. Conforme Carlos Alberto Mattos (2018), obras de cunho pessoal e autobiográfico marcaram a produção nacional nos últimos anos e, em grande medida, com o trabalho de realizadoras mulheres. Além de Elena, Diário de uma Busca (Flávia Castro, 2011), Os Dias com Ele (Maria Clara Escobar, 2013), Morada (Joana Oliveira, 2013), Uma Longa Viagem (Lúcia Murat, 2012) e os mais recentes Fico te Devendo uma Carta sobre o Brasil (Carol Benjamin, 2020) e Êxtase (Moara Passoni, 2020), por exemplo, exploram agruras familiares ou íntimas para refletir sobre questões sociais, históricas e políticas mais amplas, como a própria ditadura militar (1964-1985), tematizada, em maior ou menor medida, por quase todas elas. Trata-se de filmes, sugere Paola Labbé (2017), que almejam exercer uma função reparadora diante de sofrimentos individuais e coletivos.

Entretanto, como nos lembra Denise Tavares (2017), o protagonismo feminino no terreno do documentário ainda espelha a condição subalternizada das mulheres. Segundo Karla Holanda (2017a), os documentários dirigidos por elas ganhariam 
${ }^{1}$ Nesse contexto, é importante o trabalho de Helena Solberg, que a partir de $A$ entrevista (1966), começou a propor representações nas quais sua autoinscrição narrativa operava como dispositivo político. Para Holanda (2017b), observa-se um impulso de subjetividade na obra da realizadora, muito influenciada pelos estudos feministas.

${ }^{2}$ Cabe destacar, no entanto, que não entendo que essa "autoria feminina" corresponda a uma perspectiva de ver a realidade a partir de uma identidade natural ou essencialista. Compreendo, a partir de Paul B. Preciado (citado por Sara Llano, 2014), que se trata de um processo em que a mulher, um sujeito político subalternizado, reivindica a escritura - em diferentes suportes e linguagens - como uma arma de transformação para redefinir e reinterpretar processos sociais.

${ }^{3}$ A título de comparação, o documentário mais visto nos cinemas em 2019, conforme dados da Ancine, foi Estou me guardando para quando o carnaval chegar, de Marcelo Gomes, que teve pouco mais de $10 \mathrm{mil}$ espectadores. A audiência típica para um documentário no Brasil é de cerca de 5 mil ingressos vendidos.

${ }^{4}$ Conforme dados divulgados pelo Observatório Brasileiro de Cinema e Audiovisual. impulso somente a partir dos anos $1970^{1}$, e em franca desigualdade. Por isso, indica a autora (2015), as narrativas que emergem nos últimos anos parecem almejar não somente o preenchimento das lacunas das histórias que ambicionam retratar, mas o preenchimento dos hiatos de representatividade de gênero do próprio cinema brasileiro. "Ou seja, não se trata somente de uma busca de uma história perdida, mas de uma busca também de si, de um espaço nem sempre ocupado" (Holanda, 2015, p. 357). Suponho, então, que Elena seja um documentário representativo desse conjunto mais dilatado de obras de autoria feminina ${ }^{2}$ que buscam, através de uma narrativa posicionada e particular, tensionar questões prementes do nosso tempo, marcadamente aquelas voltadas à condição das mulheres neste contexto.

Isso posto, o filme de Petra Costa talvez tenha sido, entre eles, o que conseguiu alcançar uma projeção mais expressiva. Elena foi o documentário mais visto em 2013 (Tavares, 2017), com mais de $57 \mathrm{mil}^{3}$ espectadores no cinema no seu ano de exibição ${ }^{4}$. O filme ficou em cartaz por 10 semanas no Rio de Janeiro e em São Paulo, além de ter circulado e ter sido premiado em diversos festivais como o Festival de Brasília, o Festival Internacional de Cinema de Guadalajara e o Festival de Havana. Atualmente, está disponível na plataforma Taturana, onde contabiliza 2401 espectadores, em 44 sessões registradas; e na Netflix, que disponibilizou todos os filmes de Petra Costa depois do lançamento de sua obra mais recente, Democracia em Vertigem (2019), indicado ao Oscar em 2020.

Ainda, Elena contou com uma forte campanha pela Internet. Conteúdos sobre o filme foram disponibilizados no site oficial e em um blog, abertos à movimentação do público. Textos, frases e vídeos enviados à produção foram publicados nesses veículos, que também reuniram críticas e resenhas. Elena arrematou cerca de 140 mil seguidores no Facebook e 1,5 milhão de visualizações no seu canal oficial do YouTube. O vídeo Quem é Elena?, encenado por atores e atrizes que assistiram ao filme e quiseram ajudar em sua divulgação, contabiliza mais de 750 mil visualizações nessa plataforma. É nela que hoje podemos encontrar os treze vídeos que exercem a função paratextual que pretendo discutir neste artigo. Os excertos, que quase compõem uma nova narrativa sobre a irmã da cineasta, somam aproximadamente 89 mil visualizações.

Dessa forma, questões politicamente fundamentais às mulheres extrapolam a diegese do filme em uma mediação cultural rizomática, na qual as conversações sobre Elena atuam na produção de novos sentidos sobre a obra. Acredito, logo, que uma reflexão sobre as dinâmicas em torno dessa produção cinematográfica possa estimular um debate interessante para pensarmos, ainda que timidamente, a potência do documentarismo feminino brasileiro. O trabalho de Petra Costa parece apontar para possíveis horizontes da produção audiovisual que não somente tematizam debates pertinentes às mulheres, como engendram formas de fazer proliferar esses discursos.

Neste artigo, irei, então, destacar algumas características que julgo centrais ao filme, como seu caráter ensaístico e (auto)biográfico, para, depois, problematizar como essas estratégias narrativas, articuladas a diferentes matérias de expressão, são acionadas para problematizar processos de constituição e elaboração de feminilidades. Em seguida, pretendo refletir sobre como os vídeos paratextuais, os excessos da obra de Petra Costa, atuam na remontagem da vida e da morte de Elena.

\section{Os vultos de Elena e as lacunas do ensaio}

${ }^{5}$ Conforme Corrigan (2015), o filme Carta da Sibéria (1958), de Chris Marker, é considerado um marco do surgimento do filme-ensaio, nomenclatura cristalizada por André Bazin ao se referir à obra, tomando como base a tradição literária e fotográfica que se instituíram no pós-guerra. Em diversas entrevistas, Petra Costa referencia Marker, apontando seu trabalho como uma de suas principais referências.
Se, como propõe T. Corrigan (2015), o filme-ensaio ${ }^{5}$ surge em um contexto em que se tentava elaborar a síntese de uma tragédia inenarrável - o Holocausto -, podemos afirmar, com o autor, sua aptidão para lidar com traumas. O ensaio, nesse sentido, tem uma vocação para os discursos impossíveis. Não por acaso, é com essa linguagem que Petra Costa sustenta a narrativa, a princípio invertebrada, disforme, de sua "memória inconsolável"; conforme Henri Gervaiseau (2015), a forma do ensaio permite que o cinema trabalhe, justamente, nos limites de sua capacidade de representação. Elena, consciente da sua própria insuficiência, é uma obra lacunar e inconclusiva à procura de "uma verdade que jamais terá em mãos" (Bense, 2018). Dessa maneira, o filme nos oferece apenas fragmentos mnemônicos que Petra tenta 
reconstituir em uma audiovisualidade poética. A diretora parece almejar, como sugere Adorno (2003), criar condições, ainda que precárias, para que um objeto neste caso, um sujeito, uma irmã morta - se torne novamente visível, mesmo que de maneira incompleta. A materialização fugidia de Elena será, inevitavelmente, rascunhada e espectral.

A obra tenta exprimir texturas da experiência subjetiva traumática, e, portanto, fissurada, de Petra Costa. Como outros documentários de cunho ensaístico, busca sobrepor imagens materiais e imagens psíquicas com intuito de figurar o trabalho, sempre melindroso, de memória (Gervaiseau, 2015). Para fabular e concretizar suas lembranças da irmã, Petra utiliza uma Super $8 \mathrm{~mm}$, a mesma câmera que, no passado, registrou Elena em vida; para filmar sua procura no presente, a diretora lança mão de uma Canon 5D, reservando, assim, estéticas distintas, embora entrelaçadas, para marcar as duas ações que impulsionam o percurso narrativo. Essas imagens são articuladas, ainda, a variadas matérias de expressão. Como pontua Gervaiseau, o filme-ensaio, de fato, se constitui em um jogo intertextual complexo - em Elena, imagens de arquivo familiares, gravações de performances teatrais, músicas diegéticas e a voz over contribuem com a arquitetura desse palimpsesto audiovisual. A narração tateante, melancólica e reflexiva de Petra, inclusive, é um artifício fundamental no processo de subjetivação da jornada da própria diretora, como coloca Denise Tavares (2017). Para a autora, esse recurso garante, também, a "universalização dos embates com a dor" (p. 203).

No ensaio, mesmo quando se discorre sobre experiências individuais, elas adquirem um caráter mais abrangente (Gervaiseau, 2015). Segundo Corrigan (2015), uma expressão pessoal pode se transformar em um debate coletivo, processo metonímico reiterado, em Elena, pelo seu caráter (auto)biográfico, capaz promover um "elo entre o singular e o universal" (Tavares, 2017). A obra estimula, como propõe Corrigan, uma "atividade do pensamento público" a partir de vivências particulares capazes de sintetizar outras que as ultrapassam. O suicídio, as relações familiares e os problemas de gênero presentes em Elena alegorizam dramas sociais. Logo, o filme se constitui como uma "escrita de si" que reverbera a vida de outros sujeitos. Ele ecoa, para mais, o lema da segunda onda do movimento feminista estadunidense dos anos 1960, ramificado em disputas atuais: "o pessoal é político".

Curiosamente, o gênero literário das "escritas de si" - originado, conforme Adorno (2003) e Bense (2018), com os Ensaios (1580) de Montaigne - começou a ser significativamente apropriado por mulheres a partir do século XIX. Segundo Maria Rita Kehl (2016), as mulheres oitocentistas passaram a reivindicar sua condição humana por meio de seus registros autobiográficos, que tentavam dar conta da experiência cotidiana marcada pela feminilidade, um objeto de reflexão, até o momento, de exclusividade masculina. No cinema, percebemos, hoje, a recuperação e a ressignificação dessa maneira de narrar, também atravessada por questões de gênero. $O$ devir feminino pôde encontrar, nesse terreno fértil, um potente lugar de autoenunciação e, sobretudo, crítica. Afinal, trata-se de um padrão cultural coercitivo e, muitas vezes, impetuoso, uma vez que "não existe mulher para quem a condição feminina não signifique uma derrota de outras pretensões" (Kehl, 2016, p. 153).

\section{As mulheres-narrativa, as escritas de si e o devir feminino}

Para Simone de Beauvoir (2016), apesar de as mulheres tentarem reclamar seu papel na elaboração do mundo, "esse ainda é um mundo que pertence aos homens" (Beauvoir, 2016, p. 17). Se a alteridade, conforme a filósofa, é uma categoria fulcral do pensamento humano e se, no jogo das diferenças, nenhuma coletividade se define sem produzir distinções e hierarquias, podemos afirmar que a mulher é, historicamente, o Outro do homem. Ele, o "Sujeito", "só se põe em se opondo: ele pretende afirmar-se como essencial e fazer do outro o inessencial, o objeto" (Beauvoir, 2016, p. 14). Dessa maneira, a mulher é uma categoria negativa, cuja determinação será, quase sempre, assinalada pela limitação. Essa inferioridade feminina depende, em muito, dos modos de inscrição dos sujeitos no discurso. Afinal, as relações de gênero, segundo Maria Rita Kehl (2016), são fruto de uma "trama simbólica que constitui a cultura, que nos designa lugares, posições, deveres, traços identitários" (Kehl, 2016, p. 23) - trama 
que as mulheres raramente conseguiram controlar. Assim, "a feminilidade é uma construção discursiva produzida a partir da posição masculina à qual se espera que as mulheres correspondam" (Kehl, 2016, p. 56).

O conjunto de predicados que compõe a ideia hegemônica da feminilidade, cristalizada, principalmente, no século XIX - como a fragilidade, a capacidade procriadora, o recato, a docilidade, a passividade - operou coercitivamente no afastamento das mulheres do espaço público. Elas seriam inaptas ao trabalho, aos estudos e a quase todos os esforços físicos. A mulher oitocentista é, conforme Kehl, uma "eterna doente". Eterna, pois sua subordinação escapa do "caráter acidental do fato histórico", como coloca Beauvoir - o feminino se apresenta como uma condição natural, essencialista, e que, por isso, desafia qualquer tipo de mudança. No entanto, o "manual de instruções" dos papéis de gênero, de acordo com Kehl, não dá conta "da tarefa de tornar-se homem ou tornar-se mulher, tornar-se sujeito do próprio desejo em oposição à alienação inicial a um discurso de autoridade" (Kehl, 2016, p. 23). A inscrição das mulheres no discurso, apesar das tentativas de sedimentação, não é fixa.

De fato, a vida das mulheres sofre uma transformação na modernidade; neste contexto, consolidam-se novos padrões discursivos que reorganizam o campo simbólico, que se torna mais vasto para a formação dos sujeitos. Apesar da forte codificação da experiência feminina, há um alargamento das suas possibilidades de manifestação através da emergência de diferentes expectativas em torno dela, muitas vezes contraditórias. Essa pluralização, no entanto, veio acompanhada, segundo Kehl, de novos sofrimentos íntimos e coletivos, do desamparo diante do destino pessoal e do desenraizamento. $O$ ajuste das mulheres aos papéis de gênero legitimados sempre se deu com conflitos, cada vez mais radicalizados.

Aos ideais de submissão feminina contrapunham-se os ideais de autonomia de todo sujeito moderno. Aos ideais de domesticidade contrapunham-se os de liberdade; à ideia de uma vida predestinada ao casamento e à maternidade contrapunha-se a ideia, também moderna, de que cada sujeito deve escrever seu próprio destino, de acordo com a própria vontade. (Kehl, 2016, p. 38)

"Para cada mulher nascida no século XIX, e ainda hoje, apresenta-se a questão de ser um sujeito" ou de "colocar-se como objeto do discurso do Outro, segundo os ideais de feminilidade construídos no mesmo período" (Kehl, 2016, p. 38). É sobre os dilemas dessa escolha que Elena parece reflexionar. Não por acaso, a imagem síntese da obra é uma releitura de Ofélia, personagem shakespeariana que se mata afogada, literal e figurativamente, "no rio de desejos e sensações, de excessos do sentir e do querer" (Brum, 2014, p. 19). Ofélia, para Márcia Tiburi (2010) é a figura da passividade, sempre referenciada pela fala de outros personagens de Hamlet, cuja morte - uma tentativa de fuga deste aprisionamento discursivo - sacraliza a imobilidade que lhe cabe na cultura dominante. "O corpo feminino se torna um corpo sem narrativa, sem história" (Tiburi, 2010, p. 315), vítima de uma alienação subjetiva. As Ofélias retratadas na obra de Petra Costa conjuram as mulheres cujos "anseios latentes não encontram lugar ou palavra" (Kehl, 2016), que sucumbiram no entrelugar de sujeito-objeto. A natureza feminina é o rio no qual, diante de uma encruzilhada, submergem, sem conseguir voltar à superfície.
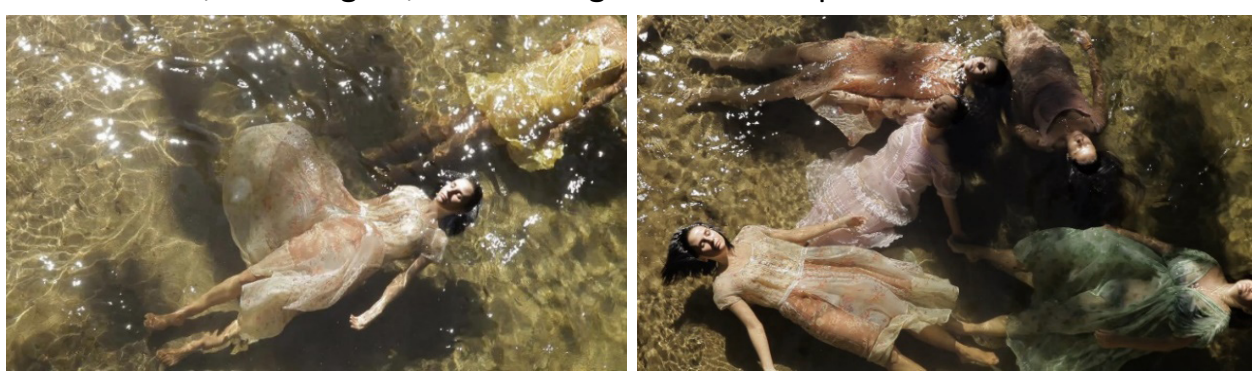

Figura 1: As Ofélias em Elena

Nota: Elena (Petra Costa, 2012). 
É contra essas águas turbulentas que se luta; um elemento que, inclusive, assinala repetidamente a narrativa do documentário. Está presente nos créditos iniciais, recobrindo flores, folhas e vestidos; emoldura, também, o rosto flutuante de Lian, mãe da cineasta, quando ela discorre sobre seu desejo prematuro de morrer; retorna numa assombrosa lembrança infantil do filme $A$ Pequena Sereia - na história original, contou Elena a Petra, a sereia perde sua voz e morre ao tentar escapar do seu destino no mar. A água compõe as performances de Elena no grupo de teatro Boi Voador e, também, os primeiros trabalhos de Petra como atriz, já enredada no trágico destino de Ofélia. Uma concha é o objeto escolhido pela irmã mais velha para fantasiar, de Nova York, um telefone sem fio imaginário com a caçula no Brasil. A água, o rio e o mar costuram a busca difluente da diretora nas correntezas da imagem, mas também são símbolos da natureza gendrada que não cessa em lhe ameaçar.

O documentário, suponho, é uma tentativa da própria Petra de sobrenadar nas águas, na verdade sintéticas, da feminilidade. Elena parece denunciar os enfrentamentos de um processo de assujeitamento doloroso e, nesse sentido, afirma a capacidade do cinema de enfrentar discursividades dominantes sobre o gênero. Representações alternativas e críticas do devir mulher, presentes nesse filme, podem estimular outros processos de subjetivação e interpelação, não ancorados em perspectivas hegemônicas. Enquanto a morte de Elena, no meio do filme, institui a agressividade de certos padrões culturais, a sobrevivência de Petra diante de uma trilha perigosa esboçada pela irmã, que sustenta o restante da narrativa, afirma a possibilidade de se resistir. O cinema, como uma tecnologia sexual, tal qual caracteriza Teresa de Lauretis (2019), é capaz, também, de mobilizar sentidos mais libertadores sobre o corpo feminino. Se, para a psicanálise, o domínio das nossas práticas linguareiras pode ser uma possibilidade de cura, podemos encarar Elena como um "fármaco-filme" que, ao reivindicar um lugar disruptivo no jogo das mediações, abre espaço para "falas emergentes, para a expressão do recalcado, do que ainda não tem lugar no discurso" (Kehl, 2016, p. 85).

Como mencionado anteriormente, o teor ensaístico do documentário permite, em grande medida, a manifestação da sua criticidade. Com Kehl, sabemos que a apropriação de certos códigos literários das "escritas de si" por parte das mulheres do século XIXe, hoje, a reinterpretação desses códigos em novas linguagens audiovisuais provocam uma "inflação do imaginário" capaz de perturbar as regras da feminilidade. As mulheres - de escritoras a diretoras - passam a reclamar uma posição de sujeito do discurso e a reordenar os sentidos de suas próprias experiências. Elena parece, até mesmo, reverenciar essas outras narrativas íntimas, autobiográficas e autorreflexivas das quais é tributário ao se ancorar, por exemplo, na materialidade das cartas e diários da personagem que titula o filme, em uma espécie de cartografia dos lugares possíveis de afirmação desse "eu" feminino em crise.

O diário é, pelo menos desde o século XIX, uma prática ritualística entre meninas adolescentes que nele encontram, segundo Philippe Lejeune (2014), uma possibilidade de subterfúgio. "O diário é um espaço onde o eu escapa momentaneamente à pressão social, se refugia protegido em uma bolha onde pode se abrir sem risco, antes de voltar, mais leve, ao mundo real" (Lejeune, 2014, p. 303). Ele pode ser uma ferramenta de construção positiva da autoimagem, sem se eximir da sua capacidade de provocar questionamentos e introspecções. O diário de Elena, descoberto por Petra aos 18 anos, foi, justamente, a semente do documentário; como um disco rígido da memória, instrumento de solidificação de vestígios, ele permitiu que a diretora se deparasse com as aflições e desejos que compartilhava, mutuamente, com a irmã. Assim como o diário, a carta também foi um gênero bastante cultivado entre as mulheres oitocentistas com pretensões autorais e um elemento marcadamente explorado na obra de Petra Costa. Conforme Kehl, a correspondência foi a forma primeira de expressão das mulheres, que constituíam, por meio dessas escritas pessoais, redes de compartilhamento e identificação.

${ }^{6} \mathrm{~A}$ única carta de Elena escrita em papel, mostrada pelo filme, é sua carta de suicídio. As últimas cartas gravadas expostas pelo filme evidenciam, talvez coincidentemente, que Elena acreditava estar perdendo sua voz. Elena, como caracteriza Mattos (2016), é ele próprio um filme-carta - para a irmã destinatária e para espectadoras - lido pela diretora em tom menor, saudoso. Ainda, as cartas de Elena para a família - ou melhor, as vídeo-cartas ${ }^{6}$, já que ela mesma experimentava escrever com a câmera - são capazes de proporcionar lampejos de sua existência, sublinhada, entre outras coisas, pela depressão. É na releitura desses videotextos que Petra, mimetizando o forte sotaque mineiro da 
${ }^{7}$ Conforme Henri Gervaiseau (2015), o ensaio pode projetar ficcionalizações; a ficção pode operar como uma "máscara do teatro" para tratar de aspectos do real. Em Elena, esse recurso torna-se ainda mais interessante ao lembrarmos que as duas irmãs trabalharam como atrizes. Por meio do teatro, Petra consegue reelaborar a vida de Elena, tão marcada por essa expressão artística. irmã, a encena pela primeira vez, obnubilando as fronteiras materiais e subjetivas que separam uma mulher da outra.

A confusão entre corpos - manifestada, também, através de outras formas de reencenação $0^{7}$ - parece se afirmar como uma das principais estratégias narrativas para tornar uma história pessoal, política. Para além de estreitar os sofrimentos compartilhados por Petra e Elena, certas escolhas retóricas enfatizam o aspecto alegórico dessa indistinção. Das tentativas da diretora de repetir os gestos da irmã, às expressões verbais que explicitam, diretamente, a indiscernibilidade entre as duas - escutamos, por exemplo, diferentes vozes sobrepostas que destacam suas semelhanças enquanto Petra, reconstituindo os passos de Elena, caminha pelas ruas de Nova York -, objetiva-se engendrar, em verdade, a escrita de um "nós", capaz ecoar experiências femininas plurais. As aflições porosas que atravessam e embaralham a vida de duas mulheres podem, também, implicar outros sujeitos interpelados por afetos similares.

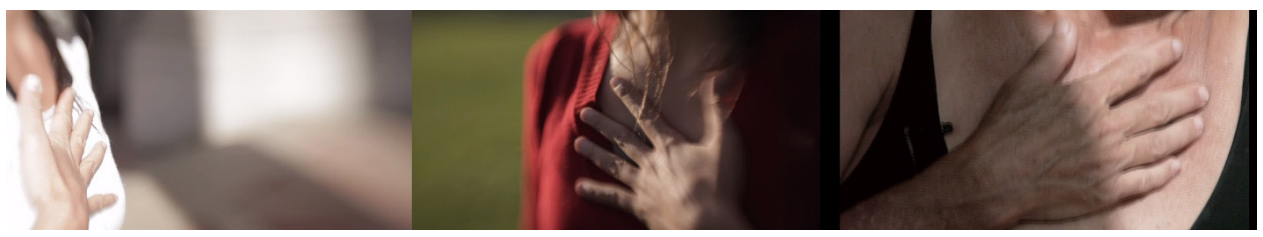

Figura 2: Petra e Lian levando a mão ao peito, como fazia Elena para falar da sua angústia Fonte: Elena (Petra Costa, 2012).

Implicam, ainda, uma terceira personagem, Lian, que assim como as filhas, manifestava a ambição de ser atriz - ela sonhava em ir pra Hollywood e beijar Frank Sinatra -, o desejo de morrer - deu-se um prazo, até os 16 anos, para encontrar um sentido na vida, quando conheceu, enfim, o pai das meninas - e a necessidade de escapar de um mundo em que se via desadaptada como mulher. As três compartilham, também, a intimidade com a câmera; no filme, misturam-se as imagens gravadas por Elena e Lian, com a Super $8 \mathrm{~mm}$ dos anos 1980, e as imagens produzidas por Petra, que restaura memórias com o mesmo equipamento. Nesse sentido, há, por vezes, uma fluidez não apenas entre as suas identidades, mas no próprio lugar da autoria cinematográfica. Subverte-se, aí, o caráter plenamente autobiográfico da obra; se o pacto desse tipo de escrita pressupõe uma relação clara entre autor, narrador e personagem, como propõe Lejeune (2014), há, em Elena, uma tentativa de superação dessa rigidez esquemática. O filme é tanto sobre Petra, quanto sobre a irmã e a mãe enlutada; é sobre "subjetividades em trânsito" (Labbé, 2017), fragmentadas e dispersas; é uma obra erguida a partir de reflexões sobre dores em alguma medida indiscrimináveis. "É desse labirinto intrincado entre posições - mãe, filha, irmã... mulheres enlaçadas (e misturadas) que fala o filme de Petra Costa. Diz também - e muito - desse lugar impossível, que é o da filha que sobrevive diante de uma mãe inconsolável" (Brum, 2014, p. 20).

Para Lejeune, "transformar a sua vida em narrativa é simplesmente viver. Somos homens-narrativa" (Lejeune, 2014, p. 86). Elena parece se afirmar, logo, como um registro da luta por sobrevivência de Petra e Lian. Como discurso, o documentário reelabora performativamente experiências de desamparo para que a diretora possa exercer, de alguma maneira, algum controle sobre sua própria história e sobre as arestas da feminilidade que atravessam, por vezes violentamente, os corpos assinalados por ela. O filme, suponho, é uma tentativa de vocalizar e resgatar Ofélias emudecidas; assim, Petra, Elena e Lian, mas não só elas, podem e precisam ser mulheres-narrativa.

\section{As franjas de Elena: as reinterpretações do paratexto}

A retomada de uma discussão sobre Elena, ensejada por este artigo, é mobilizada não somente pela forma como a obra coteja questões de gênero - cuja presença no debate público é, hoje, inquestionável -, mas pela maneira como se instaurou sua conversação social. Como defendido anteriormente, os treze vídeos divulgados no canal do YouTube e no site oficial do filme - apenas uma parte dos produtos que ampliaram os debates sobre o documentário - podem ser encarados como discursos 
${ }^{8} \mathrm{~A}$ música foi adaptada pela artista a partir do texto de Guimarães Rosa, autor que influenciou Elena em sua carreira como atriz. No documentário, a escutamos declamar, repetidamente, as palavras de Corpo de Baile: "Bem, estou adoecida de amor. Põe a mão em mim, que eu viro água. Volta, me escolhe, me leva". paratextuais. Esse conceito da literatura, tomado a partir de Gérard Genette (2018), dá conta dos textos que "cercam e prolongam" a obra principal, garantindo sua presença no mundo e norteando sua recepção e consumo. Os paratextos engendram espaços de acompanhamento, estratégicos na ação com o público, com intuito de orientar e amparar o acolhimento da narrativa. Esses excessos de Elena parecem, então, potencializar os debates propostos pelo filme em sua mediação e circulação cultural.

Nesses vídeos, observa-se a retomada de elementos fulcrais à construção da crítica à feminilidade presente no documentário de Petra Costa, destacados anteriormente. As imagens das Ofélias, por exemplo, iniciam essa narrativa ao mesmo tempo paralela e complementar; os três primeiros excertos - intitulados, respectivamente, I Turn to Water, Ofélias e Memórias do Mar - recuperam a discussão do filme acerca de uma natureza feminina que se deve enfrentar para não morrer. No primeiro vídeo, observamos uma única Ofélia, ao som da música homônima de Maggie Clifford ${ }^{8}$, dançando no rio que representa sua sina. No segundo, várias jovens são figuradas nas suas buscas do "vir-a-ser-mulher" - entre elas, Petra - numa expansão do fragmento metafórico que sumariza a grande questão da produção documental. Os tecidos dos vestidos se misturam, mais uma vez, com folhas e vitórias régias, consubstanciando, visualmente, mulher e natureza. No terceiro vídeo, particularizase essa narrativa que se inicia coletiva - na contracorrente do filme, que vai do drama pessoal aos problemas comuns -, aproximando-a de experiências vividas, somente, pelas duas irmãs. Nele, tenta-se reelaborar a primeira ida de Petra à praia - que, desde pequena, parece ter medo do poder destruidor das águas. Recupera-se, nessas passagens, a dinâmica da universalidade/particularidade de um devir feminino coercitivo e tormentoso, que se voltará, emblematicamente, contra a diretora e sua irmã.

A centralidade dos diários e cartas - importantes lugares de registro das histórias das mulheres, conforme apontado neste trabalho - também é reafirmada nos vídeos paratextuais. No quarto trecho, Elena num Diário Japonês, observamos Petra (re) iniciar sua busca pelas escritas pessoais de outra pessoa, um possível amigo ou namorado da irmã, que relata, à diretora, uma ida prosaica ao cinema nos anos 1990. No oitavo, aprendemos que foi através de um recorte de jornal escondido nos diários de Elena que Petra conseguiu rastrear seus colegas do grupo Boi Voador. No último trecho, de número treze - Memórias de uma Criação aspira-se ao registro do processo de realização do documentário. A equipe majoritariamente feminina - reflete sobre inspirações, desafios da montagem, a construção do roteiro e as transformações inerentes a toda dinâmica criativa, em uma espécie de diário audiovisual do próprio filme. Afirma-se, aí, as principais estratégias narrativas da obra junto ao público: a associação não linear entre imagem e som; a busca da fluidez na figuração da memória; o anseio por enquadramentos dançantes, conquistados com o abandono do tripé; as inspirações shakespearianas; a ambição de organizar uma narrativa representativa da experiência de outros sujeitos. Evidencia-se, ainda, que se almejava retratar apenas alguns aspectos da sua personagem-título, sem pretensões de apresentar uma perspectiva realista. Se o diário de Elena, a menina-mulher, orientou o percurso de edificação do filme, este diário de Elena, o documentário, orienta o percurso de sua recepção, conforme, obviamente, os desejos de sua realizadora.

No sexto vídeo, Uma Passagem pelos EUA, que se inicia com Elena armada de sua Super $8 \mathrm{~mm}$, temos acesso a imagens diarísticas do seu cotidiano e, também, às cartas de e para ela, em vídeo e áudio. (Re)descobrimos, pela variedade dos registros, que essa forma de comunicação era a preferida da então adolescente para atualizar família e amigos acerca de suas aventuras novaiorquinas. É nesse extrato audiovisual que escutamos a voz original dessas correspondências, dubladas no documentário por Petra, lembramos, numa primeira tentativa de reencenação. Nesse sentido, com a manifestação de uma enunciação mais juvenil, mais fina, mais mineira, Elena vai ganhando, nas narrativas paratextuais, um corpo próprio, distinto da caçula que vê, nela, sua própria vida espelhada.

Há, nos paratextos audiovisuais, uma perda do embaralhamento identitário que assinala, tão marcadamente, a obra principal. Neles, dispõe-se de uma maior variedade de imagens de arquivo de Elena, que vai se despindo de seu caráter 
${ }^{9}$ Quem sugeriu que Petra tirasse todos os homens do filme, após assistir a um corte inicial da obra por intermédio de João Moreira Salles, foi ninguém menos que Eduardo Coutinho - que, inclusive, sempre privilegiou mulheres em cena. fantásmico. Se, no filme original, poucas gravações e fotografias se repetem, em uma espiral da memória, nas narrativas que o excedem reconhecemos melhor a fisionomia, os modos e as diferentes facetas da irmã da diretora. Elas se tornam, assim, sujeitos plenamente distinguíveis. O efeito de separação dos corpos é ainda mais acentuado nos vídeos em que outras possíveis personagens - o pai, a avó, os amigos de Elena do Boi Voador, a família com a qual a jovem se hospedou em sua estadia nos Estados Unidos - entram em cena, oferecendo seus depoimentos para o documentário. Nas entrevistas, Elena vai se tornando mais encarnada e mais múltipla, distanciando-se da imagem precariamente conservada pela lembrança de Petra. Elena, como memória coletiva, tem seu papel especular de irmã mais velha diluído entre outros possíveis - de amiga confidente, de estudante de intercâmbio, de atriz em ascensão. As dificuldades compartilhadas entre as duas e outras - mulheres, no processo do "vir a ser", vai perdendo, nos paratextos, o protagonismo temático. Petra não ocupa mais o lugar de personagem, mas de uma entrevistadora em busca de um retrato, mais bem delimitado, de uma irmã que pouco conheceu.

Ao apreciarmos a obra à luz dos paratextos que a ela se referem, é possível imaginar o que o filme poderia ter sido - uma biografia de Elena, elaborada a partir das declarações das testemunhas da sua vida. Elena teria tido, talvez, um destino mais parecido com o de Ofélia: se tornaria, tão somente, um objeto do discurso alheio. Ao organizar uma narrativa excedente, que evidencia aquilo que foi deixado fora do filme ${ }^{9}$, Petra Costa revela as camadas de suas escolhas criativas, propondo um outro tipo de reflexividade, voltado para seus processos de montagem, de seleção de planos e de engendramento de uma voz autoral implicada numa jornada que é, também, subjetiva. Em uma reiteração do desejo ensaístico do documentário, é possível problematizar, a partir dos discursos paratextuais, a própria feitura dessa experiência cinematográfica.

\section{Dançando com Elena: breves considerações}

Elena propõe um recorte temático politicamente relevante, capaz de abarcar discussões que afetam as mulheres, grupo socialmente subalternizado. Contempla, em sua estrutura narrativa, elementos discursivos que potencializam experiências desses sujeitos: reclama-se as "escritas de si" dos ensaios, dos diários e das cartas para perscrutar as contradições da feminilidade - um padrão cultural hegemônico que mascara sua condição histórica, situada e, não obstante, abusiva. Ainda, o documentário de Petra Costa conseguiu, por causa de uma produção paratextual, ampliar sua capacidade de circulação, alargando as conversações sobre o devir mulher para além das salas de cinema. Outros sentidos sobre a obra puderam percorrer o ciberespaço, atingindo e implicando um número maior de espectadores. Para além de possibilitar esse alcance maximizado, os paratextos audiovisuais parecem reiterar, também, a criticidade de Elena, ratificando a relevância de certas matérias de expressão e jogos de linguagem, ou propondo novas inflexões na reflexividade que a obra reivindica.

Porém, é preciso ponderar sobre quais mulheres o documentário parece tratar. As experiências de sofrimento diante da feminilidade doméstica, adoecida e frágil dizem respeito a uma mulheridade branca, burguesa, e pouco correspondem às espoliações que afetam pessoas racializadas, das classes populares. Expulsos da própria categoria "mulher", como pondera María Lugones (2011), esses sujeitos sempre tiveram que enfrentar as agruras do trabalho braçal e exploratório. As manifestações da violência se dão por outros caminhos, muitas vezes distantes daquele sublinhado pelo "ideal feminino" que marginaliza as personagens figuradas na obra de Petra Costa. Não obstante, a produção cinematográfica não perde sua importância; trata-se de uma narrativa limitada, circunscrita a um aspecto, específico, do devir mulher, mas que pode apontar para novas formas de gestar a crítica às estruturas de opressão que privam certos corpos do direito de ordenar, discursivamente, suas próprias vidas. 


\section{Referências}

ADORNO, T. (2003). O ensaio como forma. In T. Adorno, Notas de Literatura (pp. 15-45). Duas cidades/34.

BEAUVOIR, S. (2016). O segundo sexo: Fatos e mitos. Nova Fronteira.

BENSE, M. (2018). O ensaio e a sua prosa. In P. R. Pires (Org.), Doze ensaios sobre o ensaio (pp. 100-124). IMS, 2018.

BRUM, E. (2014). Em busca do próprio corpo. In Elena: O livro do filme de Petra Costa (pp. 16-21). Arquipélago, 2014.

CORRIGAN, T. (2015). Sobre a história do filme ensaio: De Vertov a Varda. In T. Corrigan, O filme ensaio: Desde Montaigne e depois de Marker (pp. 53-78). Papirus, 2015.

COSTA, P. (Diretora). (2012). Elena [Filme]. Busca Vida Filmes. http://www.elenafilme.com/.

DE LAURETIS, T. (2019). A tecnologia de gênero. In H. B. Hollanda (Org.), Pensamento feminista: Conceitos fundamentais (pp. 121-155). Bazar do Tempo, 2019.

GENETTE, G. (2018). Paratextos editoriais. Ateliê.

GERVAISEAU, H. A. (2015). Escrituras e figurações do ensaio. In F. E. Teixeira (Org.), O ensaio no cinema (pp. 92-119). Hucitec, 2015.

HOLANDA, K. (2015). Documentaristas brasileiras e as vozes feminina e masculina. Significação, 42(44), 339-358. https://doi.org/10.11606/issn.2316-7114. sig.2015.103434

HOLANDA, K. (2017a). Da história das mulheres ao cinema brasileiro de autoria feminina. Famecos, 24(1). https://doi.org/10.15448/1980-3729.2017.1.24361

HOLANDA, K. (2017b). Helena Solberg: Entre o pessoal e o político. Devires, 14(2), 184-203.

KEHL, M. R. (2016). Deslocamentos do feminino. Boitempo.

LABBÉ, P. (2017). Documental y experiencia introspectiva: Relaciones, correspondencias y tensiones para explorar el espacio de las prácticas cinematográficas autorrepresentacionales. Devires, 14(2), 226-251.

LEJEUNE, P. (2014). O pacto autobiográfico: De Rousseau à Internet. Editora UFMG.

LLANO, S. M. (2014, 4 de fevereiro). "Si la escritura no es un arma, estamos perdidos". El Espectador. https://www.elespectador.com/noticias/cultura/si-laescritura-no-es-un-arma-estamos-perdidos

LUGONES, M. (2011). Hacia un feminismo descolonial. La manzana de la discordia, 6(2), 105-119. https://doi.org/10.25100/lamanzanadeladiscordia.v6i2.1504

MATTOS, C. A. (2016). O cinema de fato: Anotações sobre o documentário. Jaguatirica.

MATTOS, C A. (2018). Documentário contemporâneo (2000-2016). In F. P. Ramos, \& S. Schvarzman (Orgs.), Nova História do Cinema Brasileiro (vol. 2, pp. 474-512). Sesc.

TAVARES, D. (2017). Documentário biográfico e protagonismo feminino. In K. Holanda, \& M. Tedesco. Feminino e plural: Mulheres no cinema brasileiro (pp. 199-212) Papirus, 2017.

TIBURI, M. (2010). Ofélia morta - Do discurso à imagem. Estudos feministas, 18(2), 303-318, https://doi.org/10.1590/S0104-026X2010000200002 